\title{
EFFECT OF MESENCHYMAL BONE MARROW STEM CELLS ON THE PERIODONTAL LIGAMENT OF INDUCED DIABETIC RATS
}

\author{
Yasser Abd-Elraouf Mohamed ${ }^{1}$, Rasha Mohamed Taha ${ }^{2}$, Laila Sadek Ghali ${ }^{3}$
}

DOI: $10.21608 / d s u .2021 .23966 .1026$

Manuscript ID: DSU-2002-1026 (R5)

\section{KEYWORDS}

Diabetes,

Periodontal ligament,

Stem cells.

- E-mail address: Yasser_biology_dr@dent.svu.edu.eg

1. Assistant lecturer in Oral Biology Department, Faculty of Dentistry, South

2. Assistant Professor of Oral Biology, Faculty of Dentistry, Suez Canal University, Ismailia, Egypt

3. Professor of Oral Biology, Faculty of Oral and Dental Medicine, Cairo University, Cairo, Egypt.

\begin{abstract}
Introduction: Considering the Diabetes mellitus (DM) as one of the oldest conditions characterized in humans, it has been recognized since antiquity and considered as a major health problem at present. There is a need for efficient treatment. Aim: The aim of the present investigation was to find out whether stem cells can alleviate the well documented side effects of streptozotocin induced diabetes mellitus on the periodontal ligament of adult male albino rats. Material and Methods: Sixty adult male albino rats with body were used in this investigation. They were divided into the following three groups; Group 1: consisted of 20 animals and served as controls; Group 2: consisted of 20 animals, they were subjected to a single intraperitoneal injection of streptozotocin in a dose of $60 \mathrm{mg}$. $/ \mathrm{kg}$ body weight for induction of diabetes mellitus; Group 3: consisted of 20 animals. They were subjected to induction of diabetes mellitus in the same way as group 2 animals. One week later, the animals were subjected to a single intravenous infusion of mesenchymal bone marrow stem cells. At the end of the experiment one week later the animals were euthanized by cervical dislocation, their jaws dissected out, decalcified then processed for A. histological examination (Hematoxylin and Eosin stain) B. transmission electron microscope. Results: Histological examination in the present work showed that the treatment of diabetic rats with stem cells resulted in amelioration of the degenerative effects of diabetes on the periodontal ligament in group 2 and regenerative changes of stem cells in group 3 compared to the control group 1 . Electron microscopic examination of the PDL showed marked regenerative changes in the density of collagen. Conclusion: Diabetic albino rats treated with stem cells revealed partial improvements, mostly in the arrangement of the fibers of periodontal ligament. The ultrastructural features showed normal fibroblasts.
\end{abstract}

\section{INTRODUCTION}

Diabetes mellitus (DM) is a metabolic issue characterized by hyperglycemia because of an imperfection in insulin emission, activity or both which if not appropriately controlled can prompt long haul spin-off of harm, damage of different organs. The administration of diabetes with no symptoms is as yet a test to the medicinal framework. Dysglycemia is a subjective term used to portray blood glucose (BG) that is abnormal without defining a threshold because of vulnerability about ideal BG ranges and the present understanding that even somewhat raised BG levels can lead to significant problems ${ }^{(1)}$. 
Metabolic disturbances in starches, lipids, and proteins result from the significance of insulin as an anabolic hormone. Low levels of insulin as well as insulin resistance of target tissues, at the level of insulin receptors, are in charge of these metabolic variations from the normal. The seriousness of side effects is because of the sort and length of diabetes $^{(2)}$

Insulin resistance in type 2 diabetes patients expands the interest for insulin in insulin-target tissues. In addition to insulin resistance, the expanded interest for insulin couldn't be met by the pancreatic $\beta$ cells because of deformities in the capacity of these cells ${ }^{(3)}$.

Hyperglycemia (and its results) is the most imperative element influencing bone quality, so that powerful glycemic control is vital for treatment and counteractive action of diabetic osteoporosis. The suitable utilization of against diabetic operators ought to further help advance bone development or potentially avoid bone resorption. In addition to bringing down plasma glucose levels and advancing anabolic bone capacity, insulin can likewise improve creation of proteoglycans, the segments of the gel-like extracellular network of ligament giving protection against osteoarthritis in overweighed DM patients ${ }^{(4)}$.

Patients with inadequately controlled diabetes are at more serious hazard to create periodontal ailment which begins with gingivitis, then with poor glycemic control advances to cutting edge periodontal disease ${ }^{(5)}$.

Stem cells can differentiate into many cell types. The two characterizing properties of stem cells are endless self-renewal and the capacity to differentiate into different cell types. There are two noteworthy classes of stem cells: pluripotent that can turn out to be any cell in the grown-up body, and multipotent that are confined to turning into a more constrained population of cells ${ }^{(6)}$.

Stem cells can possibly turn out to be any kind of fully differentiated cells, for example, a myocyte, platelet, hepatocyte and brain cell. The undifferentiated cells can quickly separate in a few organs, for example, bone marrow and gut to repair and supplant the harmed tissues ${ }^{(7)}$.

There are two essential sources of stem cells: adult stem cells and embryonic stem (ES) cells. Besides the normally present stem cells in human body, initiated pluripotent stem (iPS) cells have been as of late produced falsely through hereditary control of substantial cells ${ }^{(8)}$.

Multipotent stem cells gathered from bone marrow (BM) have been utilized since the 1960's to treat leukemia, myeloma and lymphoma. Since cells there offer ascent to lymphocytes, megakaryocytes and erythrocytes, the estimation of these cells is effectively comprehended in treating blood growths. As of late, some advance has been accounted for in the utilization of cells got from bone marrow to treat different sicknesses. For instance, the capacity to shape entire joints in mouse models ${ }^{(9)}$.

The pancreas is an organ of first area to search for the stem cells. Studies on animals have demonstrated that the accessibility of little measures of pancreatic tissue would reestablish the greatest pancreatic $\beta$-cell mass. This is because of the replication of separated $\beta$-cells of pancreatic pipes and dedifferentiation of these cells to pluripotent cells that thusly deliver more $\beta$-cells ${ }^{(10)}$.

In the present work, it was worth shedding light on the possible modulatory effect of stem cells on the periodontal ligament and alveolar process of induced diabetic rats. 


\section{MATERIALS AND METHODS}

Sixty adult male albino rats with body weight ranging from $180-200 \mathrm{~g}$ were used in this investigation housed in Faculty of Pharmacy Sinai University. They were divided into the following groups: -

Group1: consisted of 20 animals and served as controls.

Group2: consisted of 20 animals, they were subjected to a single intraperitoneal injection of streptozotocin in a dose of $60 \mathrm{mg} / \mathrm{kg}$ body weight for induction of diabetes mellitus ${ }^{(11)}$.

Group3: consisted of 20 animals, they were subdivided as follows:

SubGroup 3.1: consisted of 10 animals. They were subjected to induction of diabetes mellitus in the same way as in group 2 animals. One week later, the animals they were subjected to a single intravenous infusion of mesenchymal bone marrow stem cells. The cell number was calculated by hemocytometer for intravenous administration $\left(1.5 \times 10^{3}\right.$ $10^{6}$ ) cells per rat in $0.2 \mathrm{ml}$ phosphate buffer saline and slowly injected into the tail vein of rat over two minutes period using a 22 gauge needle ${ }^{(12)}$ to study the effect of the injected.

SubGroup 3.2: consisted of 10 animals. They were used for isolation and culture of bone marrow stem cells, at the Biochemistry Department, Faculty of Medicine, Cairo University.

Preparation of the mesenchymal bone marrowderived stem cells were carried out according to Gnecchi and Melo ${ }^{(13)}$.

At the end of the experiment, the animals of different groups were euthanized by cervical dislocation, their jaws were dissected out. Those of the right side were fixed in $10 \%$ neutral buffered formalin, decalcified in 10\% EDTA solution. The specimens were then washed properly under running water, dehydrated by transferring through ascending grades of alcohol, then transferred to xylene to clear the specimens from alcohol. The specimens were infiltrated with paraffin wax and embedded in the center of the paraffin wax blocks. The embedded specimens were sectioned 6 microns thick. The sections were mounted on clean glass slides and stained with:

- Hematoxylin and eosin stain for histological examination and detection of any structural changes in the arrangement of fibers

- Preparation of specimens for T.E.M: Small specimens of average size one cubic mm. were immediately cut from the periodontal ligament and alveolar bone of the decalcified jaws of the left side in the region of the molar areas and prepared for transmission electron microscope (TEM) examination as follows:

Specimens were rapidly fixed in $3 \%$ phosphate buffered glutraldehyde (PH 7.2) for 1-2 hours (primary fixation), then washed in 3 changes of phosphate buffer (PH 7.2) 15 minutes each. Specimens were post fixed in $1 \%$ buffered Osmium tetroxide at $4^{\circ} \mathrm{C}$ for $1-2$ hours and then washed thoroughly in the buffer. Specimens were then dehydrated in ascending grades of ethanol. Final dehydration and clearing were carried out in propylene oxide for 30 minutes.

Embedding was then carried out in oven-dried gelatin capsules using fresh epoxy resin and left to polymerize in an oven at $60^{\circ} \mathrm{C}$ for 24-36 hours. Semi thin sections (1-2 microns thick) were cut and stained with toulidine blue for 45 seconds to be examined with light microscope for orientation and localization of the site to be examined by the electron microscope.

Ultrathin sections (0.06 microns) were cut using ultramicrotome and glass knives and then mounted on copper grids. Staining was carried out with saturated uranyl acetate in 50\% ethanol for 30 minutes, then washed for several times in distilled 
water followed by staining with lead citrate for 5 minutes. Finally, examination was carried out using the T.E.M (JEOL 1000) in the cancer institute, Cairo University.

\section{RESULTS}

\section{A. Hematoxylin and eosin results:}

\section{Group 1 (control group):}

The gingival group of fibers attached to the cervical part of the cementum and extended to the free and attached gingiva, where they fuse with the fibrous tissue of the gingiva. The interdental or trans-septal group of fibers extending from the cementum of one tooth to the cementum of adjacent tooth crossing above the crest of the alveolar bone Figure (1A). The PDL/ bone interface appeared to be smooth; no osteoclastic activity was observed Figure (1B).

\section{Group2 (Diabetic Group)}

Periodontal ligaments of this group showed degenerative changes in the form of detachments and dissociation of the principle fibers, a lot of Howship's lacuna and osteoclasts on the surface of the bone Figure (2A) The attachment epithelium of this group showed an outstanding feature, which was their extreme apical migration. Figure (2B)

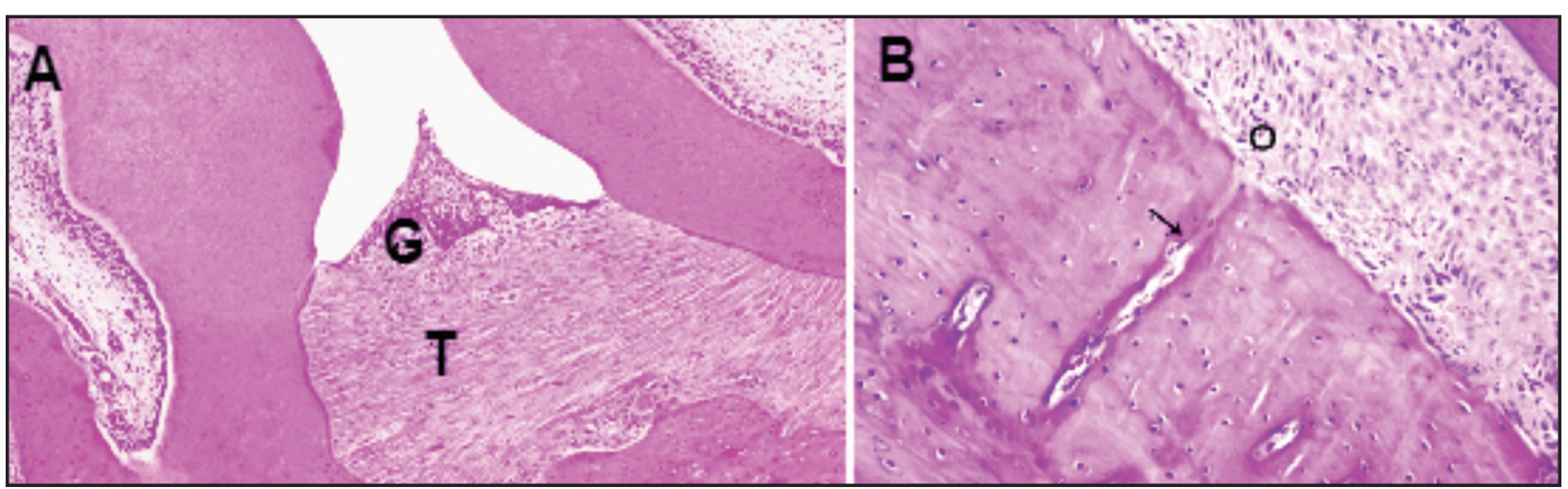

Fig. (1) A photomicrograph of periodontal ligament (PDL) of control animal showing A. a normal gingival (G) and transeptal (T) group of fibers. B. oblique group of fibers $(\mathrm{O})$ and part of alveolar bone proper having Zuckerkandle and Hirschfeld canal (arrow) and smooth interface with the periodontal ligament with no evidence of osteoclastic activity (H\&E.orig.mag.100)

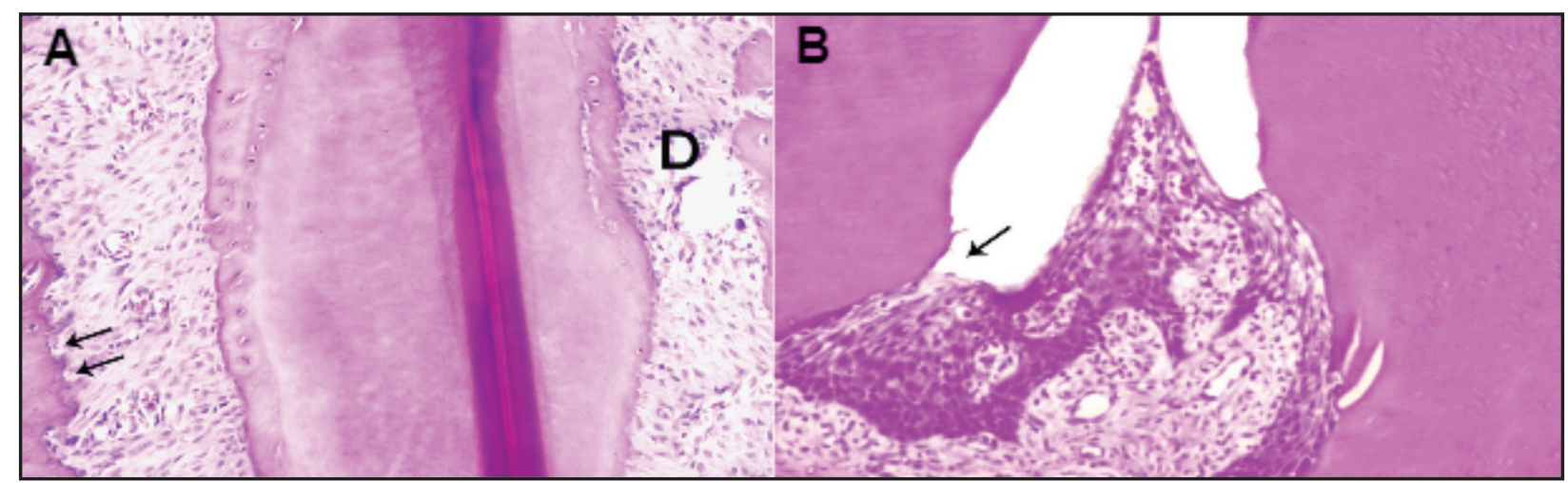

Fig. (2) A photomicrograph of PDL of diabetic animal showing higher magnification of oblique fibers with dissociation (D) and a lot of Howship's lacuna on the bone surface (arrows). B. marked apical migration of the attachment epithelium (arrows). (H. \& E., Orig. Mag. 400) 


\section{Group 3 (treated with stem cells)}

Periodontal ligaments of rats of this group showed improvements, mostly in the arrangement and association of the fibers of PDL. Compared to diabetic group, the fibers mostly regained their arrangement and association together in bundles. Figure $(3 \mathrm{~A}, \mathrm{~B})$

\section{B. Transmission Electron Microscopic Results:}

\section{Group 1 (control group):}

The electron microscopic examination of the PDL of this group revealed the normal ultrastructure of the collagen bundles that were either cut longitudinally or transversely extending between the bone and cementum. According to the direction of section, the fibroblasts were either spindle, stellate or rounded in shape the fibroblasts were presented with large rounded or oval nuclei. Figure $(\mathbf{4 A , B})$

\section{Group 2 (Diabetic Group):}

Electron microscopic examination of the PDL of this group ensured the histopathological findings where there were marked destruction and marked reduction in density of the collagen fibers leaving a lot of debris and dilated blood vessel Figure $(\mathbf{5 A}, \mathbf{B})$

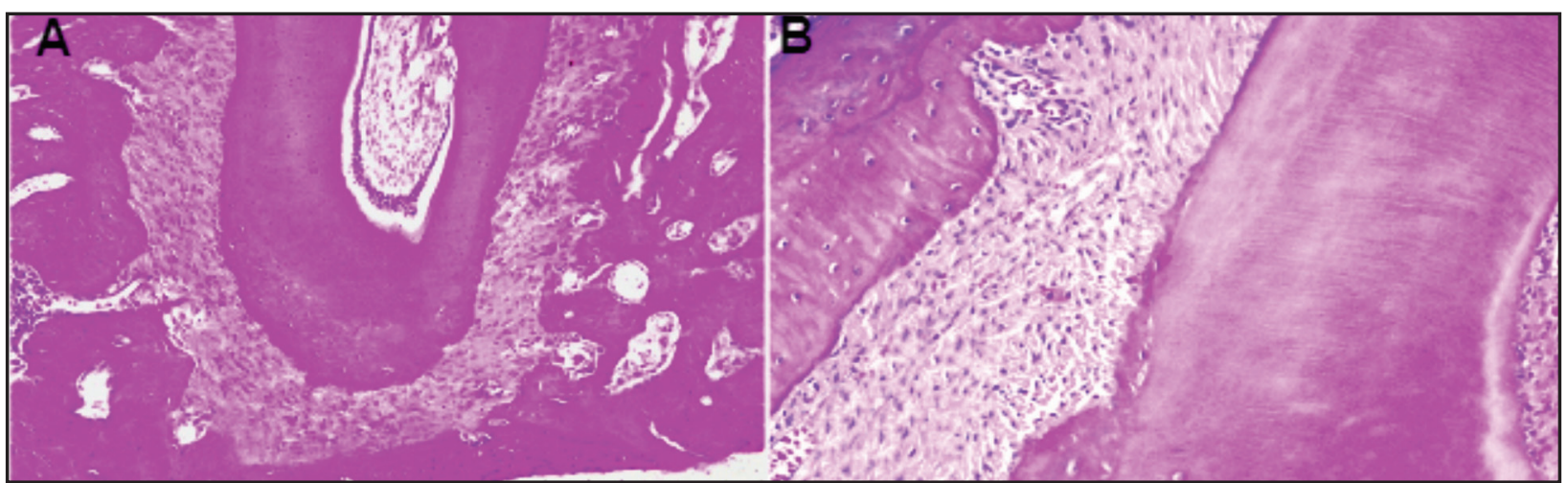

Fig. (3) A. a photomicrograph of PDL of a diabetic animal treated with stem cells showing increased density of collagen fibers of PDL with normal fiber attachment to cementum and bone, B. increased density of collagen fibers of PDL with normal fiber attachment to cementum and bone. (H\& E., Orig. Mag.200).

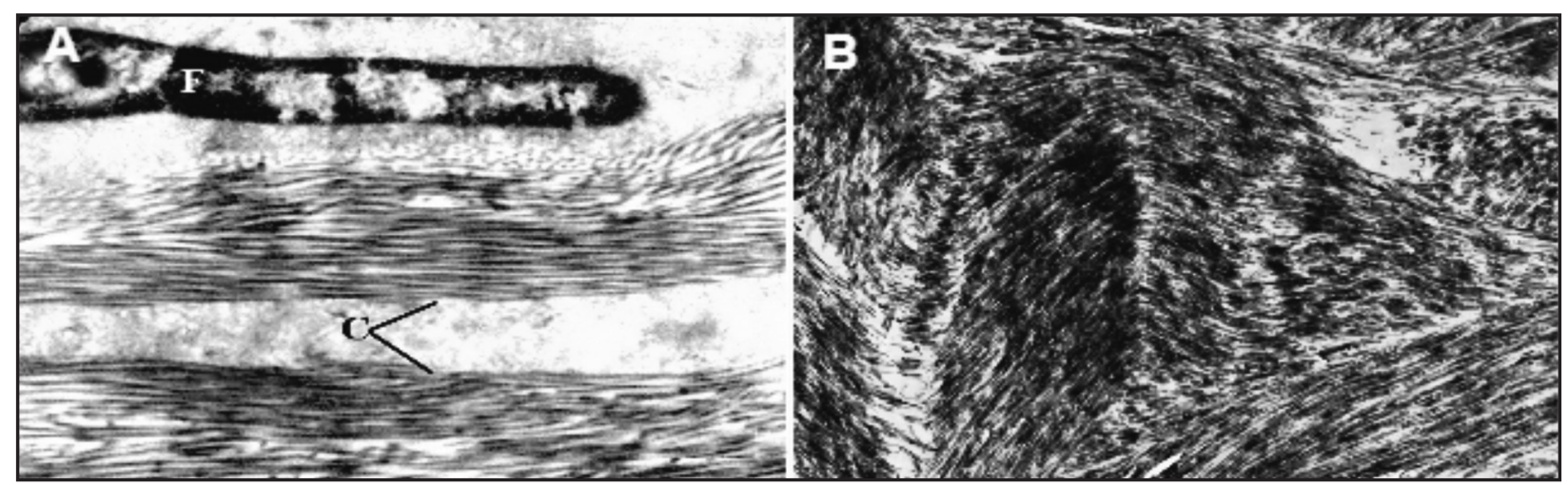

Fig. (4) A. an electron micrograph of the periodontal ligament of control rats showing normal ultrastructure of the fibroblast (F) and collagen fiber bundles $(\mathrm{C})$ that were cut transversely. B. normal ultrastructure of the collagen bundles that were either cut longitudinally or transversely (Uranyl acetate \& lead citrate.A x 4000,B.x6000). 


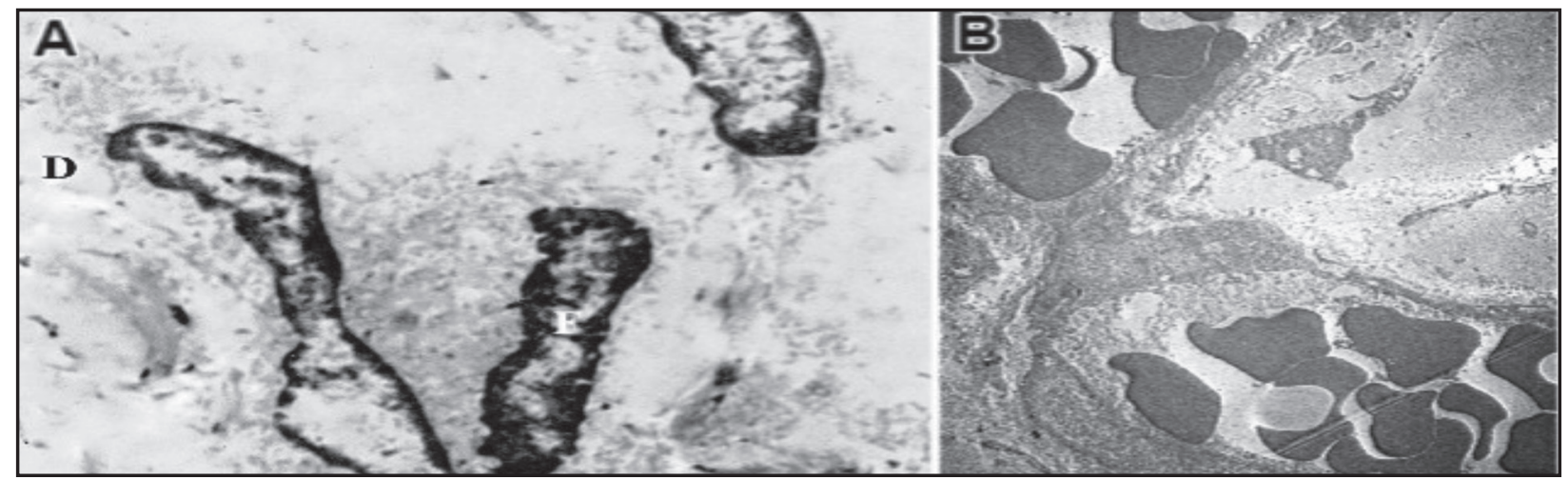

Fig. (5) A. An electron micrograph of the periodontal ligament of diabetic rats showing shrunken fibroblasts (F) among degenerated collagen fibers (D). B. showing markedly dilated blood vessel (uranyl acetate \& lead citrate.A. x 2000, B. x 5000).

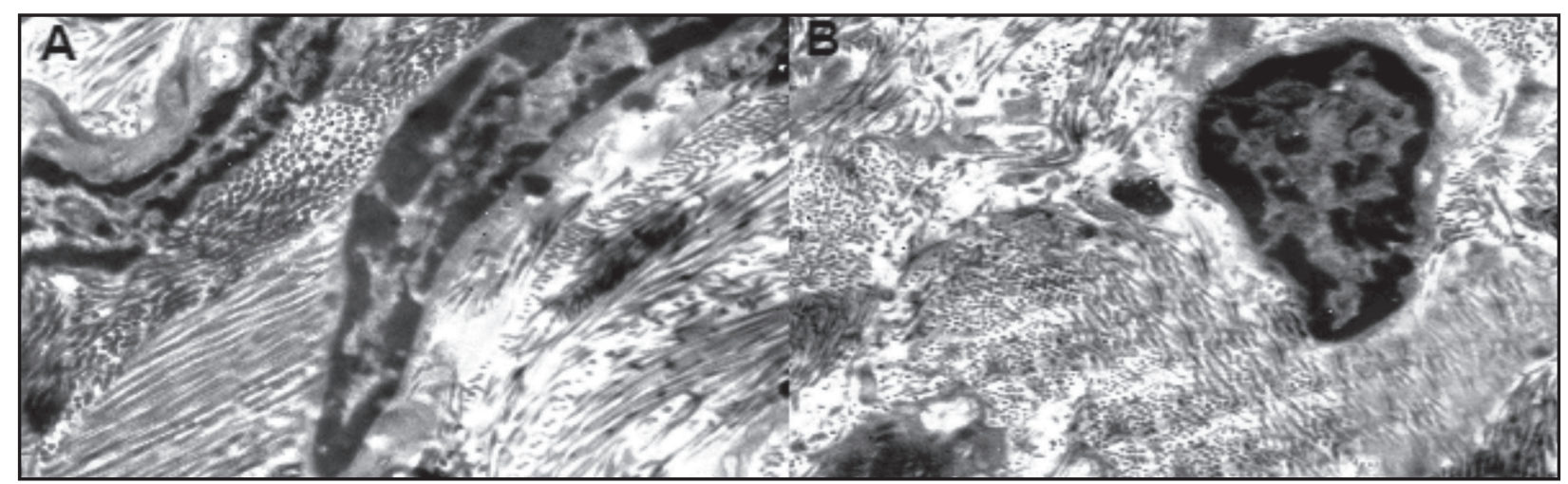

Fig. (6) A. An electron micrograph of the periodontal ligament of stem cells treated animal showing marked increase in the density of collagen fibers. B. marked regeneration in the fibroblasts $(\mathrm{F})$ and collagen fibers. (Urany acetate \& lead citrate. A. $x$ 10000, B.x5000)

\section{Group 3 (treated with stem cells):}

The ultrastructural features of the PDL of this group showed marked regenerative changes in the density of collagen fibers. Where the collagen fibers were arranged in large and thick bundles overlapping each other. There were minimal inflammatory cells, normal fibroblasts. (Figure 6A, B).

\section{DISCUSSION}

In the present work, the periodontal ligament and alveolar process was the tissue of choice for studying the link between oral and systematic health. The periodontal ligament one of the supporting structures of the tooth.
Poor glycemic control in patients with diabetes has been associated with an increased risk of progressive loss of periodontal attachment and alveolar bone over time ${ }^{\left(14,{ }^{15}\right)}$ However; other studies have shown only a marginal or insignificant relationship between glycemic control and periodontal status ${ }^{(16,17)}$.

Streptozotocin (STZ) was the drug of choice in this study to induce diabetes as it had low mortality rate and high tolerance by the experimental animals than alloxan. Also, it can be given easily by different routes and its diabetogenic action was rapid and permanent as it is known to destroy the beta cells of islets of Langerhans ${ }^{(18)}$. 
In the current study diabetes mellitus was induced by intraperitoneal injection as a single dose of $60 \mathrm{mg} / \mathrm{Kg}$ body weight of streptozotocin.

After one week of streptozotocin injection, animals were not considered diabetic unless they demonstrated serum glucose level greater than $250 \mathrm{mg} / \mathrm{dl}$ (normal serum glucose level was $65 / 110 \mathrm{mg} / \mathrm{dl}$ ). These animals showed the cardinal symptoms of diabetes as polydypsia, polyurea and polyphagia which is in accordance with what was reported by Anderson et al. ${ }^{(19)}$.

The structural results of the present study showed marked histopathological changes in periodontium of the diabetic rats. The histological results of the present study revealed that diabetes affected the periodontium and resulted in multiple morphologic alterations. Microscopic examination of the diabetic albino rats' periodontal ligament using H\&E stained sections revealed several structural changes. These changes included degenerative changes in the form of disorientation, detachments and dissociation of the principle fibers. The attachment epithelium showed extreme apical migration.

The duration of the patient being harassed with diabetes seemed to influence periodontal wellbeing, to be specific, the more extended the length is, the more terrible the periodontal wellbeing and more clinical attachment loss there is ${ }^{(20)}$.

Stem cell research offers a particularly effective potential method for cell transplantation and tissue regeneration because the conventional tissue transplantation solutions are limited by factors, such as insufficient donor tissue and graft rejection and failure. Stem cells on the other hand are able to regenerate new tissue and restore function. They are capable of renewing themselves through cell division and can be induced to become tissue or organ-specific ${ }^{(21)}$.
In the present study treatment of diabetic rats with intravenous infusion of mesenchymal bone marrow derived stem cells resulted in marked improvement of the collagen fibers of the PDL with increased density and grouped in thick bundles. The attachment epithelium showed no noticeable apical migration. Marked regeneration and attachment of the collagen fibers to the bone\& cementum were noticed.

Periodontal ligament stem cells (PDLSCs) can even be isolated from extracted teeth. PDLSCs have demonstrated the capacity to regenerate periodontal tissues (cementum, periodontal ligament and alveolar bone) in experimental animal models ${ }^{(22)}$.

The regenerative ability of mesenchymal stem cells is attributed to the fact that they can migrate to the damaged tissue area where they can carry out different mechanisms in Rejuvenation of cells and tissues. These mechanisms range from differentiation into lineages of the target cells, fusion with the damaged tissue and secreting a wide range of cytokines and other factors to ameliorate the interaction of the mesenchymal stem cells with the injured tissue ${ }^{(23)}$.

These bone marrow cells have been suggested as an easy, accessible source for multipotent stem cells that could potentially Trans-differentiate and/ or repair other non-hematopoietic organs ${ }^{(24)}$.

\section{CONCLUSION}

Streptozotocin induced diabetes caused various histological and ultrastructural degenerative effects on the periodontal ligament. Diabetic albino rats treated with stem cells revealed that marked improvements, mostly in the arrangement and association of the fibers of PDL. 


\section{REFERENCES}

1. Inzucchi SE, Bergenstal RM, Buse JB, Diamant M, Ferrannini E. Management of hyperglycaemia in type 2 diabetes: a patient-centered approach. Position statement of the American Diabetes Association (ADA) and the European Association for the Study of Diabetes (EASD). Diabetologia 2012; 55:1577-1596.

2. Kharroubi AT, Darwish HM. Diabetes mellitus: The epidemic of the century. World J Diabe 2015;6: 850-852.

3. Halban PA, Polonsky KS, Bowden DW, Hawkins MA, Mather KJ. $\beta$-cell failure in type 2 diabetes: postulated mechanisms and prospects for prevention and treatment. Diabe Care 2014;37:1751-1758.

4. Wongdee K, Charoenphandhu N. Osteoporosis in diabetes mellitus: Possible cellular and molecular mechanisms. World J Diabe 2011;2:41-48.

5. Loe H. Periodontal disease: The sixth complication of diabetes mellitus. Diabe Care 1993;16:329-334.

6. Biehl JK, Russell B. Introduction to stem cell therapy. J Cardiovasc Nurs 2009;24 :98-101.

7. Albini A, Iwamoto Y, Kleinman HK. A rapid in vitro assay for quantitating the invasive potential of tumor cells. Cancer Res 1987;47:3239-3245.

8. Alipio Z, Liao W, Roemer EJ, Waner M, Fink LM, Ward DC. Reversal of hyperglycemia in diabetic mouse models using induced-pluripotent stem (iPS)-derived pancreatic $\beta$-like cells. Proc Natl Acad Sci 2010;107:13426-13431.

9. Marion NW, Mao JJ. Mesenchymal stem cells and tissue engineering. Methods Enzymol 2006;420:339-361.

10. Seaberg RM, Smukler SR, Kieffer TJ, Asghar Z, Wheeler MB, Korbutt G. Clonal identification of multipotent precursors from adult mouse pancreas that generate neural and pancreatic lineages. Nat Biotechnol 2004;22:1115-1124.

11. Fahim MA, Hasan MY and Alshuaib WB. Cadmium modulates diabetes-induced alterations in murine neuromuscular junction. Endocr Res 2000; 26: 205-217.

12. Tielens S, Verhasselt B, Liu J, Dhont M, Van Der Elst J, Cornelissen M. Generation of embryonic stem cell lines from mouse blastocysts developed in vivo and in vitro: relation to Oct-4 expression. Reproduc 2006; 132: 59-66.
13. Gnecchi M, Melo LG. Bone marrow mesenchymal stem cells, isolation, expansion, characterization, viral transduction and production of conditional medium. Methods Mol Biol 2009; 482:281-294.

14. Taylor GW, Burt BA, Becker MP, Genco RJ, Shlossman M, Pettitt DJ. Non-insulin dependent diabetes mellitus and alveolar bone loss progression over 2 years. J Periodontol 1998;69(1):76-83.

15. Seppala B, Ainamo J. A site-by-site follow-up study on the effect of controlled versus poorly controlled insulin-dependent diabetes mellitus. J Clin Periodontol 1994;21(3):1615 .

16. Barnett ML, Baker RL, Yancey JM, MacMillan DR, Kotoyan M. Absence of periodontitis in a population of insulin-dependent diabetes mellitus patients. J Periodontol 1984;55(7):402-5.

17. Tervonen $\mathrm{T}$, Karjalainen $\mathrm{K}$, Knuuttila M, Huumonen S. Alveolar bone loss in type 1 diabetic subjects. J Clin Periodontol 2000;27(8):567-71.19.

18. Anderson LC. Salivary gland structure and function in experimental diabetes. Biomed Revi1998; 9: 107-119.

19. Anderson LC, Garrett JR, Suleiman AH and Chan KM. Secretory edema in diabetic submandibular glands during parasympathetic nerve stimulation: relationship to microvascular abnormalities in streptozotocin-treated rats. Comp Biochem Physiol 1992; (103A): 145-149.

20. Popescu D, Rica AM, Ciuca A, Puiu I, Mota M, Surlin P. Periodontal changes in patients with type 1 diabetes-clinical aspects. Rom J Oral Rehabil 2014; 6:88-93.

21. Nguyen TT, Mui B, Mehrabzadeh M, CheaY, Chaudhry Z, Chaudhry K, Tran SD. Regeneration of tissues of the oral complex: current clinical trends and research advances. J Can Dent Assoc 2013; 79:81.

22. Seo B-M, Miura M, Sonoyama W, Coppe C, Stanyon R, Shi S. Recovery of stem cells from cryopreserved periodontal ligament. J Dent Res 2005;84:907-912.

23. Semedo P, Burgos Silva, M, Donizetti-Oliviera, C, amara MS. How do mesenchymal stem cells repair?. Stem cells clin research 2011; 21:83-94.

24. Couzin J. A shot of bone marrow can help the heart. Sci 2006; 313:1715-1716. 